\title{
Teaching and Learning in First Year Seminars
}

\author{
Louise Allsopp \\ School of Economics, Adelaide University \\ Adelaide, Australia
}

louise.allsopp@adelaide.edu.au

\section{Executive Summary}

The author compares the relative successes of three different teaching techniques in seminars for a first year university course. This paper tests to see if there is one overriding approach that enables all students to learn effectively in seminars or whether different students benefit from different teaching techniques.

An experiment is carried out on a subset of a first year group in Semester 1, 2001 for five separate fiftyminute sessions. Five groups are taught using one teaching technique based around the idea of passive learning. Five further groups are taught using a second technique based on active learning within small groups. The remaining three groups face a third approach based on a combination of the other two techniques. The students are monitored throughout the course. The assessment is based on (a) written and verbal tests at the end of the course, (b) participation in seminars and (c) attendance at the seminars and at the written/verbal tests. The author considers the performance of the students for each of these categories in the light of a personality questionnaire designed to ascertain preferred learning styles. She also considers the students' responses to a final questionnaire that asks for the best and worst features of the seminar in which they were placed. The investigation aims at establishing if there is a link between student performance in tests, preferred learning styles and the teaching methods adopted. The ultimate goal is to deliver seminars that offer the students the best possible learning environment.

While the author finds that participation figures are considerably higher for one particular teaching style (namely a combination of the techniques adopted in the other two methods), no such correlation is found for any of the other tests. Furthermore, there is no obvious link between preferred learning type and test performance. It is also noted that in the post-test questionnaires there is only high praise from the students for the combination approach but criticism for each of the other two approaches. The results from this experiment would suggest that there is no single teaching style that produces higher student test results. However, since the participation figures are high for the combination approach and the student response to this is so positive, the combined approach of "teaching around the cycle" may be optimal for this course. Furthermore, the author also notes that individual tutor qualities may be influencing the data yet this variable is very difficult to measure or quantify.

Keywords: learning styles, teaching methods, small-group work.

\footnotetext{
Material published as part of this journal, either on-line or in print, is copyrighted by the publisher of the Journal of Information Technology Education. Permission to make digital or paper copy of part or all of these works for personal or classroom use is granted without fee provided that the copies are not made or distributed for profit or commercial advantage AND that copies 1) bear this notice in full and 2) give the full citation on the first page. It is permissible to abstract these works so long as credit is given. To copy in all other cases or to republish or to post on a server or to redistribute to lists requires specific permission and payment of a fee. Contact Editor@JITE.org to request redistribution permission.
}

\section{Introduction}

The aim of this paper is to highlight a challenge faced by many university teachers and to consider a practical method of dealing with the situation. Biggs (1994) summarizes the problems faced by teachers in higher education. He notes that resources are constrained and hence class sizes are on the increase with the emergence of mass methods of teaching and assessment. Restrictions also 
exist in the structure of the degree programs themselves and the manner with which they are delivered. The end result is that many students have little contact with their lecturer and the lecturer has limited chance to assess the course and the progress of the students. Since little can be done to change the overall picture, the lecturer must work "smarter" and use the teaching time available in the best possible way. A weekly seminar in which the large lecture group is divided into smaller groups of fifteen students or less could hold the key. This provides an opportunity for the student to learn in a less formal environment than the lecture theatre. Furthermore, the lecturer has direct contact with the students. However, the pertinent question is, "How should the seminar be organized?"

There exists a vast literature in the area of education and while space permits the inclusion of a detailed analysis, Biggs (1994) provides an excellent summary of the competing models. He outlines the various theories of learning and notes how opinion on these has evolved over time. However, his most salient points concern the link between research and teaching. He notes the importance of a sound theory underlying the practicalities of teaching but also that the theory should be derived from the individual teaching context.

In light of this, the author compares the relative successes of three different teaching techniques in seminars for a first year university course in Finance. The aim is to deliver seminars that offer the students the best possible learning environment. This paper tests to see if there is one overriding approach that enables all students to learn effectively in the seminars of this course or whether different students benefit from different teaching techniques.

\section{Background}

The author of this paper is neither a psychologist nor theorist in the area of education. Quite simply she is on the front line of teaching and seeks practical, sensible approaches to teaching seminars in a large first year university course.

At this stage it should be noted that the same arguments may be applied to courses in Information Technology. Certainly, there is growing demand for these courses in universities worldwide since companies demand graduates to be competent in the use of computing in the workplace. Hence the same problems of large class sizes are encountered. However, of equal importance is the fact that Finance and IT are inextricably linked (See the work of Penceck and Bialaszewski (2001)). Hence techniques that aid both disciplines would be welcomed.

This experiment is carried out on a subset of the first year Finance group at Adelaide University in Semester 1, 2001. It is based on a pilot experiment run on the same course in the previous year, the results of which may be found in the proceedings of the OOICTL Business 2000 International Conference, (2000). There are 450 students registered to take this course. They come from a variety of academic backgrounds and have very different requirements of the course. For instance, some will aim to major in a completely different area and hence choose Finance as a one-year option to get a basic overview of the subject. At the other end of the spectrum there are students who wish to major in Finance. It follows that the course must be relevant for those wanting a one-year option but also for those wishing to pursue Finance in later years.

In terms of course structure, each student faced two lectures per week for the duration of the twelveweek semester. They were also required to sign up for a weekly seminar. The students were divided into 30 seminar groups according to their timetable commitments. The experiment was then carried out on thirteen such groups for five separate fifty-minute sessions. Five groups (i.e. ninety six students) were taught using one teaching technique. A further five groups were taught with a second technique. The remaining three groups faced an alternative approach that consisted of a combination of the other two techniques. 


\section{Experiment}

\section{Different Approaches to the Seminar}

A frequently used technique is to treat the seminar as the opportunity for a mini lecture. The students are required to prepare a response to the task in question before the seminar time. During the seminar, the lecturer uses the whiteboard or overhead facility to supply a sample response to the task. The relative merits of this approach are discussed in Brown and Atkins (1996). This is one of the teaching methods adopted in this experiment.

A second approach used in the experiment concerns small group activities. The benefits are well documented in the literature but are summarized particularly well in Andresen (1993). Here the same task is set and students come prepared. However, learning becomes an active rather than passive activity. The lecturer still has an important role to play in guiding the session but is no longer providing the answers. The emphasis is on engaging activity and encouraging participation. This technique is important in IT education as noted by Onay (2001) and also Novitski (2001).

This approach is certainly not new. Indeed, small group teaching has its roots in the work of Plato's teacher, Socrates who used subtle questioning as his strategy! While times may have changed, the principles behind small group teaching remain the same, namely the development of communication and intellectual skills plus the personal development of the students. Small group teaching did not really emerge until the late nineteenth century and the term "small group teaching" encompasses a whole host of different techniques. There are many different possibilities here. For an excellent coverage of the different small group learning methods see the Supplemental Instruction, University of Missouri-Kansas City (1995) and for a discussion of the perceived benefits of this approach see Luker (1987).

In this experiment the jigsaw learning method, also known as the "syndicate" approach, is adopted. The group is divided into smaller sub-groups and each works on some portion of the problem. At the end of an allotted time frame, they then share their results with the rest of the group. This method was chosen since it is suitable for the nature of the tasks presented to the students in this particular course. It is also widely used (Collier 1969, 1985) since it has been shown to be effective when a complex issue can be decomposed into smaller tasks.

The third method adopted in the experiment consists of a combination of the two techniques described above. In particular, the tutor incorporates the mini lecture method with periods of group work. The seminar then contains a period of reflection where the student formulates his/her own ideas in isolation and then a further period of active learning in groups. This combination of reflective and interactive learning is not new to the IT literature. Indeed this has been adopted by Kinshuk (2001) in the development of an intelligent tutoring system.

\section{Index of Learning Styles}

Prior to the experiment, the students were asked to complete a learning styles questionnaire to ascertain their preferred methods of learning. This information then provided a benchmark to establish whether the mode of teaching in their seminar group corresponded to their preferred mode of learning. It was stressed that this exercise was entirely voluntary and that a refusal to take part would in no way disadvantage the student in this course.

At the time of writing, there are a number of excellent tests that have been used in educational settings and also in the workplace. These include the Myers-Briggs Type Indicator based on Carl Jung's concept of psychological types. Participants are categorized into sixteen different learning style types. For further details and applications see Lawrence (1994) and McCaulley (1990). A second learning style model is that of Kolb (1984). Again participants are classified but this time into four basic types of learners. The 
Herrmann Brain Dominance Instrument (1990) considers learning in the context of reliance on different quadrants of the brain. Once more, there are four basic learning types. Finally, there is the FelderSilvermann model used in this analysis. Applications of this are predominantly in the engineering field (Felder and Silvermann (1988) and Felder (1996)).

There are a number of reasons why this index was chosen above the others. First, it was easy to implement. Second, it was straightforward from the student's point of view. Clearly it was crucial that the student be able to understand the questions and be able to interpret the results. Third, it was noted (Felder, 1996) that the choice of model was immaterial since each provided the same basic information.

Felder and Silvermann classify student learning in five ways. First they consider sensing versus intuitive learners. Sensing learners are ones that are geared towards facts, procedures and problem solving. They are practical and hence good at hands-on work and pay attention to detail. The intuitive learner, by contrast, focuses on theories and their meanings while being conceptual and innovative in their approach. They are quick to understand new concepts and more likely to be able to deal with mathematical formulations than the sensing learner.

The second distinction is between the visual and verbal learner. Visual learners prefer an environment where material is presented through diagrams, pictures and charts. Verbal learners prefer the written word and spoken explanations. The third category considers inductive versus deductive learners. Inductive learners look at the specific to the general scenario. Deductive learners are more comfortable with the general to the specific.

The next classification considers whether learners are active or reflective. Active learners benefit from trying things out and working with other people to find a solution. Reflective learners prefer to think things through on their own first and to work alone. Finally, learners may be sequential or global in their approach. Sequential learners prefer to learn material in an order and in small steps. The global learner, however, is more comfortable when learning in large leaps. He/She tends to grasp the big picture before seeing the finer details and small connections.

Felder and Silverman provide an index of learning styles that is based on the testing of four out of five of these categories (omitting the inductive/deductive category). The test consists of 44 multiple-choice questions relating to simple day-to-day procedures which are answered by either (a) or (b). There are 11 questions for each category. The test itself can be carried out using the computer or with pen and paper. After the students had completed the questionnaire, the totals for each category were summed to establish the extent to which each student preferred one mode of learning to another in each category.

At that stage, the author discussed each individual student's results with him/her confidentially before discussing with the group how different types of learners could help themselves in the university environment. Felder notes how each type of learner can benefit and it is hoped that having publicized this within the course, students can obtain a richer understanding of how they function as learners and what they can do to help themselves.

\section{Experimental Design}

Each group faced the same set of seminar questions presented to them in the course booklet alongside their lecture notes at the outset of the course. For each group, attendance for each of the five sessions was noted and an ice breaking exercise carried out at the start of the first session in order that the students were introduced to their colleagues. For the groups in which the mini lecture method was adopted, the tutor then progressed through the tasks set for the students and provided answers on the board at the front of the room stopping at regular intervals to ask for questions and comments. For the groups in which the jigsaw method was used, the tutor formed subgroups at the start of each session. The members in each group were rotated on a weekly basis to ensure that students were working with different colleagues every time. Each subgroup was asked to consider one of the seminar questions and was given a 
fixed time limit to consider their response. When the time was up, each group presented its work and then an open forum followed when questions and comments were taken from the rest of the group. This process was then repeated for the remaining four weeks of seminars.

At the end of the course, the students were assessed by written and verbal tests. These tests were only being offered to students within the experimental groups and hence they could not be made compulsory. However, the degree of participation was also useful information for the experiment. The written test comprised three short answer questions that were related to those seen in seminars. They had 25 minutes to attempt these. After a short break, the group was divided into subgroups and each group presented with a problem relating to the material in the course. They were given five minutes to discuss the subject area and give a small presentation on that area. During this period of discussion, the tutor circulated amongst the groups assessing each student's level of participation.

At the end of the written and verbal tests, students were presented with a questionnaire designed to discover what they liked and disliked about their seminar program. In particular, the aim was to rate the response of students who were in seminar groups not consistent with their preferred method of learning. Had the seminars helped the student to learn outside his/her preferred method of learning? This marked the end of the experiment.

\section{Assessment}

The students were assessed in a number of ways:

(a) Attendance at seminars and at the final tests

(b) Participation in seminars

(c) Written test

(d) Verbal test

(e) Questionnaires

(f) Results from Index of Learning Styles

Categories (a) to (d) were assessed on a points basis and the results tabulated in the following subsection. At each stage, a comparison was made between the different groups.

The three questions in the written tests were graded in the same way as in the exam i.e. each one was worth six marks. It was believed that this would be of more help to the students in their revision for the final exam. For the verbal test, each student was awarded a maximum of six marks.

Students received a mark for attendance at each of the seminars and at the final written and verbal tests. A grade of one was awarded for each seminar attendance and zero for non-attendance. This means that the maximum grade available was six marks.

Student participation was assessed again on a mark of 1-6 in terms of student contribution to a session and general attitude to learning. It is recognized that this is a subjective way of evaluating degree of participation and hence the results of this section should be viewed with a degree of caution.

The questionnaires were considered in the light of which group the student was from, the results from his/her learning styles index and the grades obtained in categories (a)-(d).

\section{Evaluation of Results}

Table 1 contains some basic statistics from the experiment. The first point to note here is that while there were 96 students in the mini lecture and also the jigsaw groups with 54 in the combination groups, only 108 people in total attended the written/verbal tests at the end of the course. Furthermore, only 74 of 


\begin{tabular}{|l|c|}
\hline No. of Students in Mini Lecture Method & 96 \\
\hline No. of Students in Jigsaw Method & 96 \\
\hline No. of Students in Combination Groups & 54 \\
\hline No. Submitting Learning Styles Questionnaire & 74 \\
\hline No. Attending Written/Verbal Tests & 108 \\
\hline No. Commenting on Seminar Style in Post Test Questionnaire & 23 \\
\hline
\end{tabular}

Table 1: Preliminary Results from Experiment

these people submitted learning styles questionnaires. Without distributing yet another questionnaire it is difficult to ascertain the reason for such a low response rate. One can only speculate at the reasons behind this low response.

The second point concerning these preliminary statistics concerns the end of course questionnaire on seminar style. The students were asked for the best and worst aspects of their seminars. Only 23 people specifically addressed the style of the seminar with the majority noting personal characteristics of their tutor i.e. whether the tutor had made the subject interesting or whether they had been approachable. Of those who did comment on seminar style, it was interesting to note that there were no complaints for the methods adopted in the combination groups. Indeed, this approach attracted high praise. By contrast, there were some people who detested the jigsaw approach and some who were equally opposed to the mini lecture method. It was little surprise to discover that these people had strong preferences for the opposite learning style from the group in which they were placed.

\begin{tabular}{|l|l|l|l|}
\hline Test Type & $\begin{array}{l}\text { Aver- } \\
\text { age } \\
\text { Grade } \\
\text { for } \\
\text { Mini } \\
\text { Lec- } \\
\text { ture } \\
\text { Groups }\end{array}$ & $\begin{array}{l}\text { Aver- } \\
\text { age } \\
\text { Grade } \\
\text { for Jig- } \\
\text { saw } \\
\text { Groups }\end{array}$ & $\begin{array}{l}\text { Average } \\
\text { Grade for } \\
\text { Combina- } \\
\text { tion Groups }\end{array}$ \\
\hline Written & 9.1 & 8.1 & 7.5 \\
\hline Verbal & 3.0 & 2.4 & 1.7 \\
\hline Attendance & 4.5 & 4.6 & 4.3 \\
\hline $\begin{array}{l}\text { Participa- } \\
\text { tion }\end{array}$ & 3.9 & 4.6 & 5.3 \\
\hline
\end{tabular}

Table 2: A Comparison of Test Results Between the Two Types of Seminar.
Table 2 contains the results for the students in each type of seminar. Note that the author does not provide any formal statistical tests since in many circumstances, the sample size is too small to provide any meaningful measure and hence may be misleading. It provides the average grades for each group since space permits an examination of each of the individual cases. The table details results from each of the categories: attendance, participation, written test and verbal test. The first point of interest concerns the written and verbal test results. In each case, the students in the mini lecture group score slightly higher on average than those in the other groups. However, the margin here is not statistically significant. Attendance is very even across groups on average. In contrast participation is significantly higher in the combination groups than in the others. A tentative conclusion to be drawn here is that while test grades do not appear

to be strongly linked with seminar type, participation is higher when a combination of teaching styles is used.

In Table 3 the author provides a discussion of the test results in the light of the outcomes from the index of learning styles. For each group, the number of students falling into each category within the index is summed and tabulated. The correlation between student types and their test results is then considered. 


\begin{tabular}{|c|c|c|c|c|c|c|c|c|c|c|c|c|c|c|c|}
\hline \multirow{3}{*}{$\begin{array}{c}\text { Learning } \\
\text { Style } \\
\text { Index } \\
\\
(1) \\
\end{array}$} & \multirow{3}{*}{$\begin{array}{l}\text { No. in } \\
\text { Mini- } \\
\text { Lecture } \\
(2) \\
\end{array}$} & \multirow{2}{*}{$\begin{array}{c}\text { No. in } \\
\text { Jigsaw } \\
\text { Group } \\
(3) \\
\end{array}$} & \multirow{2}{*}{$\begin{array}{c}\text { No. in } \\
\text { Combo } \\
\text { Group } \\
\text { (4) } \\
\end{array}$} & \multicolumn{3}{|c|}{$\begin{array}{c}\text { Average } \\
\text { Attendance }\end{array}$} & \multicolumn{3}{|c|}{$\begin{array}{c}\text { Average } \\
\text { Written Test }\end{array}$} & \multicolumn{3}{|c|}{$\begin{array}{c}\text { Average } \\
\text { Verbal Test }\end{array}$} & \multicolumn{3}{|c|}{$\begin{array}{l}\text { Average } \\
\text { Part'n }\end{array}$} \\
\hline & & & & & (5) & & & (6) & & & (7) & & & (8) & \\
\hline & & & & $\bar{M}$ & $\mathrm{~J}$ & $\bar{C}$ & $\bar{M}$ & $\mathrm{~J}$ & $\bar{C}$ & $\bar{M}$ & $\mathrm{~J}$ & $\bar{C}$ & $\bar{M}$ & $\mathrm{~J}$ & $\bar{C}$ \\
\hline A.S.Vi.Se & 5 & 5 & 7 & 4.5 & 5.5 & 5.5 & 5.5 & 7 & 6.5 & 4.25 & 3.5 & 1.5 & 5.5 & 5 & 6 \\
\hline A.S.Vi.G & 1 & 2 & 1 & 6 & 6 & 5 & 10 & 6.5 & NA & 6 & 1.5 & NA & 6 & 5 & 6 \\
\hline A.S.Ve.Se & - & 2 & 2 & - & 5 & 5.5 & - & 7.5 & 8 & - & 3 & 2 & - & 6 & 6 \\
\hline A.S.Ve.G & 1 & 1 & 1 & 6 & 4 & 5 & 9 & 5 & NA & 4 & 4 & NA & 6 & 5 & 6 \\
\hline A.I.Vi.Se & 1 & 2 & - & 5 & 5.5 & - & 15 & $\overline{5.5}$ & - & 3 & 3.5 & - & 5 & 5 & - \\
\hline A.I.Vi.G & - & - & 3 & - & - & 5 & - & - & 4 & - & - & 0 & - & - & 5 \\
\hline A.I.Ve.Se & - & - & - & - & - & - & - & - & - & - & - & - & - & - & - \\
\hline A.I.Ve.G & - & - & - & - & - & - & - & - & - & - & - & - & - & - & - \\
\hline R.S.Vi.Se & 8 & 4 & 6 & 5.5 & 4.75 & 5 & 10 & 7.5 & 9.25 & 3 & 2 & 1.5 & 5 & 4.75 & 6 \\
\hline R.S.Vi.G & - & 3 & 3 & - & 5 & 5.5 & - & 11 & 6 & - & 3 & 1 & - & 4 & 6 \\
\hline R.S.Ve.Se & 2 & - & 3 & 6 & - & 5 & 13 & - & 9.75 & 5.5 & - & 2 & 6 & - & 5 \\
\hline R.S.Ve.G & 1 & 2 & - & 6 & 3.5 & - & 4 & 6.5 & - & 0 & 3 & - & 4.5 & 2.5 & - \\
\hline R.I.Vi.Se & 1 & - & 3 & 3 & - & 4.5 & NA & - & NA & NA & - & NA & 3 & - & 6 \\
\hline R.I.Vi.G & - & 1 & 1 & - & 6 & 5 & - & 4 & NA & - & 3 & $\mathrm{NA}$ & - & 4 & 6 \\
\hline R.I.Ve.Se & - & - & - & - & - & - & - & - & - & - & - & - & - & - & - \\
\hline R.I.Ve.G & 1 & 1 & - & 6 & 0 & - & 11.5 & 0 & - & 6 & 2 & - & 6 & 0 & - \\
\hline
\end{tabular}

Table 3: Average Results for Students in Each Category of the Learning Style Index

Note that since the index classifies student learning on four counts, there are sixteen possible combinations of learning style. While the table illustrates the numbers of students falling into each category, it should be noted that for an accurate assessment each individual score should be considered separately. The reasoning behind this is as follows. If a student has a slight preference for visual rather than verbal learning techniques, in terms of this analysis, he/she joins the "visual" category. However, students with a strong preference for visual learning will also join this same category. Thus, it follows that the students should be considered on a case-by-case basis since the index does show the extent to which students prefer one mode of learning or another.

Note that the terms in column 1 refer to the classifications of learning style: Reflective/Active, Sensing/Intuitive, Visual/Verbal and Sequential/Global. The terms M, J and C in columns 5-8 refer to those students in the mini-lecture group, jigsaw group or combination group respectively.

Notably, the majority of students are Sensing, Visual and Sequential learners with a fairly even split between active and reflective students. This raises some very interesting issues for further research since this may reflect the type of student who is attracted to Finance courses in the first place. Alternatively, it may be indicative of learning methods used in pre-university teaching. In either case, there is a large proportion of the sample with the same basic learning characteristics.

The next step in the analysis was to establish whether there was a link between preferred learning style, the groups in which the students were placed and their test performances. The main point to note here is that figures are given for average performance and hence this may not be as revealing as an examination of individual performance. However, it is still a worthwhile exercise to consider any visible trends. 
In examining average attendance, the author can find no link between learning type, teaching style and performance. Attendance appears to be uniform across all teaching and learning types and hence the conclusion to be drawn here is that students do not appear to be deterred (or equally they are deterred to the same extent!) by different seminar styles. A different story may be said for participation. Certainly, participation is high across all types for the combination groups. However, it is interesting to note that the reflective learners in the mini lecture groups score higher on average than the reflective learners placed in the jigsaw groups. While this is intuitively appealing, the opposite scenario does not hold. The active learners in the jigsaw groups do not earn higher average participation grades than those placed in mini lecture groups. While space permits a detailed analysis of each student, it would be interesting to gain a richer understanding of the dynamics in each seminar group. For instance, it may be that the participants of the mini lecture groups formed close bonds early on and hence were comfortable with class participation.

In terms of the verbal tests, the combination groups perform the most poorly on average as indicated by Table 2. In examining the reflective learners, it is apparent that those in the mini lecture groups perform better on average than those in the jigsaw groups. For the active people, the same pattern emerges with the mini lecture groups scoring a higher average grade than the jigsaw groups. This is surprising since one would have expected the active learners in the jigsaw groups to outperform those in the mini lecture groups. This same feature is seen when examining the average results of the written test. Here the reflective learners in the mini lecture method outperform the reflective learners in the jigsaw groups and combination groups although the difference between the average scores in mini lecture and combination groups is small. The active learners in the mini lecture groups once again outperform those in the jigsaw and combination groups.

One may criticize the data analysis on a number of grounds. First, the author has used averages as opposed to a detailed individual analysis. Second the author has considered the categories of learning without looking at the degree to which the students hold particular learning preferences. Third, in many categories, there are simply too few data points for the results to be meaningful. Nevertheless, the predominant feature is that there appears to be no apparent link between learning types, teaching style and test performance. This, in itself is deserving of attention.

In terms of evaluation of teaching and learning performance, there is one variable that cannot be easily measured, namely the inherent personality traits and qualities of the individual teacher. Anecdotal evidence reveals that some of the toughest math-intensive university courses earn high student praise because of the attitude of the lecturer in charge. Each of the three techniques had a different tutor each with a very different outlook and personality. It follows that this "character" variable may well be playing a role in the investigation and influencing the results, yet it is incredibly difficult to measure or quantify.

At this stage it was hoped that the student questionnaires would throw some light on the subject. As mentioned earlier, the students were asked for the best and worst feature of their own seminars. The overall aim was to see if certain personality types felt more suited to a particular teaching method. There were only 23 people out of 108 participants who specifically addressed the issue of seminar style. The remaining students considered personal aspects of the tutor and subject content. Of the minority who addressed seminar style the students who complained about their particular groups were those who had submitted a learning styles questionnaire that suggested that they were suited to the alternative teaching style. Of importance is the fact that there was only high praise from the students in the combination groups regardless of their learning types.

\section{Future Research}

This experiment does not provide any significant evidence to suggest that one teaching style is superior to another for this particular course. However, a detailed analysis on individuals would be far more ac- 
curate. Sadly, this was somewhat limited since participation in the learning styles questionnaire and also the final written and verbal tests could not be made compulsory in this institution. Hence, there is only a complete data set for a small number of students. Therefore, it would be a useful exercise to carry out such an experiment on a larger sample size and then identify individuals rather than examine mere average figures.

Furthermore, it would be useful to decompose the analysis further to examine particular groups of students. For example, the needs of the growing number of overseas students on this program are also a concern hence a test to establish their preferred learning styles would be valuable. See the work of Ledingham (1993) for a similar test. In addition, it would also be interesting to establish if preferred learning style is gender-dependent since this would have serious consequences for the structure of teaching (see Philbin et al (1995)).

As a final point, it may also be worthwhile exploring the issue of tutor personality qualities in influencing teaching and learning since this variable may be playing a significant role in this investigation.

\section{Conclusion}

The results of the experiment suggest that there is no over riding superior teaching technique for this course. The written and verbal tests suggest a small difference on average, between the students in each seminar type but this is not statistically significant. In addition, there is no observable difference in attendance figures and no obvious correlation between preferred learning style and the teaching method adopted in each group. However, when considering participation, there was overwhelming evidence in support of the combination technique that incorporated elements from each of the other two teaching styles. The final questionnaires also revealed that this technique was acceptable for all its participants.

While the author acknowledges the limitations of the data analysis in this experiment, it should be noted that the results are consistent with the approach suggested by Felder of "teaching around the cycle". He argues that when a variety of techniques is used, all students' preferred modes of learning are met to some degree. Certainly, this is true of the combination approach. Felder argues that if students are taught completely within their preferred learning styles, they do not then develop the necessary mental skills to achieve their full potential. Conversely, if they are taught solely outside their preferred learning mode, their discomfort level may be so high as to seriously compromise their learning. Felder argues that the optimal approach is to design a course which encompasses the students' preferred and less-preferred styles of learning. In this way, each student gets to work in his/her preferred learning mode for some of the time but also gets the chance to develop new learning skills.

The results from this experiment suggest no significant difference in average written or verbal test results. However, the average participation figures for the combination groups are substantially greater than for the other two teaching styles with only high praise for this particular seminar type. Therefore the technique of adopting a combination of different teaching styles would seem to be the best option for this course. As noted in previous sections, it would also be worthwhile investigating the individual tutor qualities in such an experiment. While the variable is very difficult to measure it would appear that the attitude and approach of the tutor can make an enormous difference and indeed, may be clouding the results to some degree.

Clearly, there is no single solution to the problem of teaching a large first year university course where contact time is limited. However, the seminar plays an important role in bridging the gap between student and lecturer and hence a carefully structured seminar program that considers different teaching and learning styles could make a significant difference. 


\section{References}

Allsopp, L. (2000). An Experiment to Test Two Different Teaching Techniques in First Year Business Seminars. Proceedings of the OOICTL Business 2000 International Conference, 1:81-86.

Andresen, L. (1993). What's the Use of Small Group Teaching? 50 Years of Research into Class Size, Teaching Methods and Student Learning. Technical Report. University of New South Wales.

Biggs, J. (1994). Student Learning Research and Theory - Where Do We Currently Stand? Online Available: http://www.lgu.ac.uk/deliberations/ocsd-pubs/isltp-biggs-html

Brown, G. \& Atkins, M. (1996). Effective Teaching in Higher Education. Routledge.

Collier, K.G. (1969). Syndicate Methods: Further Evidence and Comment. Universities Quarterly, 23, Autumn, 431-6.

Collier, K.G. (1985). Teaching Methods in Higher Education: The Changing Scene with Special Reference to Small Group Work. Higher Education Research and Development, 4(1), 3-27.

Felder, R.M. (1996). Matters of Style. ASEE Prism, 6(4), 18-23.

Felder, R.M. \& Silverman, L.K. (1988). Learning Styles and Teaching Styles in Engineering Education. Engr. Education, 78(7), 674-681.

Herrmann, N. (1990). The Creative Brain. Lake Lure, NC: Brainbooks.

Kinshuk. (2001). Intelligent Tutoring of Domain Skills: The Need and a Solution. Proceedings of 2001 Informing Science Conference, Krakow, Poland.

Kolb, D.A. (1984). Experiential Learning: Experience as the Source of Learning and Development. Englewood Cliffs, NJ: Prentice-Hall.

Lawrence, G. (1994). People Types and Tiger Stripes. $3^{\text {rd }}$ Edition. Gainsville, FL: Center for Applications of Psychological Type.

Ledingham, J. (1993). TAG Newsletter: The Multicultural Classroom. Online Available: http://mrn.mediaservices.ubc.ca/facdev/services/newsletter/

Luker, P.A. (1987). Some Case Studies of Small Group Teaching. PhD Thesis, University of Nottingham, UK.

McCaulley, M.H. (1990). The MBTI and Individual Pathways in Engineering Design. Engr. Education. 80, 537-542.

Novitski, J. E. (2001). Critical Issue in the Administration of an Integrating Capstone Course. Proceedings of 2001 Informing Science Conference, Krakow, Poland.

Onay, Z. (2001). Leveraging IT for Distance Education: An Interdisciplinary Graduate Program on the Internet. Proceedings of 2001 Informing Science Conference, Krakow, Poland.

Penceck, T. \& Bialaszewski, D. (2001). An Application of Active Learning and Distance Education. Proceedings of 2001 Informing Science Conference, Krakow, Poland.

Philbin, B., Meier, E., Huffmann, S., \& Boverie, P. (1995). A Survey of Gender and Learning Styles. Sex Roles, 32(718), 485494.

University of Missouri-Kansas City (1995). Collaborative Learning Methods. Supplemental Instruction.

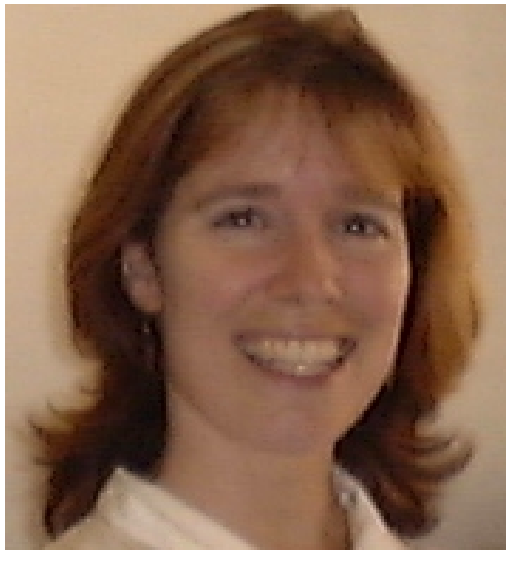

\section{Biography}

Dr Louise Allsopp is a lecturer in the School of Economics at Adelaide University, Australia, where she teaches courses in Finance and Economics. She has authored papers on the subjects of currency crises, experimental economics and education in finance and economics. 